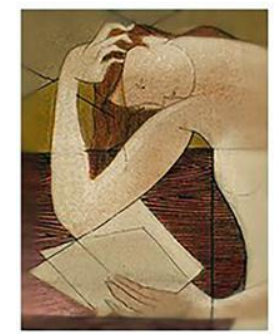

\title{
A representação do negro e do imigrante alemão em Canaã, de Graça Aranha
}

\section{Zuleica Luana Kraemer ${ }^{1}$}

\begin{abstract}
Resumo: O presente artigo tem como objetivo analisar a representação de raça na obra Canaã, de Graça Aranha. Enquanto alemães chegavam ao Brasil sem nada e tornavam-se ricos rapidamente, os negros libertos pela Lei Áurea viviam de favor ou mendigando por um prato de comida, sem ter onde morar e trabalhar. Além disso, o pensamento existente ao longo da narrativa é o de rebaixamento do povo brasileiro e de exaltação aos imigrantes.
\end{abstract}

Palavras-chave: raça; imigração alemã; literatura brasileira.

Abstract: This essay aims to analyze the representation of race, in the book Canaã by José Pereira de Graça Aranha. While the Germans arrive in Brazil with nothing and get rich quickly, the blacks released by the Lei Áurea lived in favor or mended for a plate of food, with nowhere to live and work. In addition, the existing thought throughout the narrative is the abasement of the Brazilian people and the exaltation of immigrants.

Keywords: race; german immigration; Brazilian literature.

\section{Introduzindo com um pouco de História...}

Tratar do assunto raça nunca é algo simples, seja ainda nos dias de hoje, seja na revisão da História, seja em Literatura. O tema gera desconforto, e com razão. É preciso abordá-lo ainda e cada vez mais até o dia em que não for mais necessário nenhum tipo de reparação.

Conectado ao assunto raça, quando se trata de divisão do trabalho, é preciso estar consciente de que ela se deu de formas diferentes na Europa e na América, por exemplo. Na Europa, os critérios são marxistas, ou seja, de classe social, enquanto, na América, são de raça. A configuração clássica da teoria marxista não dá conta da América, pois aqui, através do colonialismo, a questão de raça permitiu a divisão do trabalho como se deu, ou seja, escravizando índios e permitindo a manutenção de escravizados trazidos da África. A política de embranquecimento no Brasil, iniciada no século XIX, deu continuidade e reforço à divisão do trabalho por raça.

Os dominadores que atuaram no Brasil, principalmente no período colonial, foram suficientemente persuasivos a ponto de convencerem-se a si mesmos e aos

\footnotetext{
${ }^{1}$ Graduada em Letras Português/Alemão, UFRGS. Mestranda em Letras, UFRGS.
} 


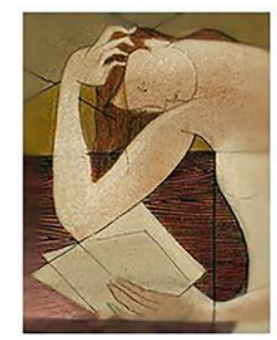

dominados. No período colonial e ainda nos dias de hoje o que sempre se quis foi chegar no patamar europeu.

Retrocedendo cronologicamente, até mesmo a questão dos direitos humanos enfrentou barreiras com a questão de raça. Os direitos humanos esbarravam no direito à propriedade e nisso está incluída a propriedade de humanos - os escravizados e as mulheres, por exemplo. Apenas no século XX a questão da cor da pele não basta para suprimir os direitos. É nesse momento que a ciência de uma forma ou outra tenta comprovar a inferioridade de mulheres, judeus, negros, sujeitos não cisgêneros, entre outros.

A história da literatura é um campo de estudos da Ciência relativamente recente - tem em torno de 300 anos. Os estudos da história da literatura universal muito claramente referem-se à Europa; por sua vez, os estudos da história de literaturas nacionais tiveram início em países como a França, a Inglaterra e a Espanha. No Brasil, os estudos da história da literatura são ainda mais recentes e têm sua referência na Europa.

A história da literatura nacional contém um aval da nacionalidade, e esta não é e nunca foi plural. Há na história da literatura nacional uma ideia de identidade que é dada pela língua. Porém, a língua nacional não é um sinônimo da língua da Literatura. São poucos os brasileiros que conseguem ter fruição lendo o cânone, por exemplo.

Felizmente, nas últimas décadas veio à tona um quantidade considerável de obras literárias escritas por e/ou tematizadas conforme a pluralidade brasileira. Em estudos acadêmicos principalmente, existe a oportunidade de ter conhecimento e desenvolver pesquisas sobre obras que nunca estiveram e nem estariam no cânone. A questão é: as obras atuais não podem ser medidas pelas clássicas ou pelo cânone.

No século XVIII, dá-se o início da formação dos Estados/emancipações nacionais. No século XIX, formados os Estados nacionais, a questão das identidades nacionais se torna imprescindível, principalmente para a representação ficcional. No Brasil, essa questão está muito ligada à natureza, ou seja, a cor local é importante para a produção literária. Todavia, o indígena que aparece é reduzido ao sujeito colonizado, e o negro é o escravizado ou o descendente dele. Tanto o índio quanto o negro não ocupam 


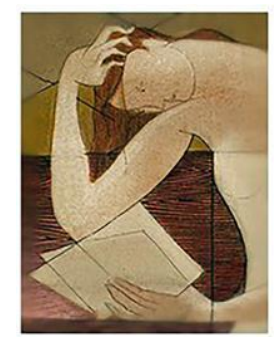

lugar central nas narrativas e, quando aparecem, não estão ali para representar o ideal brasileiro.

\section{A imigração alemã no Brasil}

É impossível pensar em imigração alemã no Brasil do século XIX sem pensar em raça. Por mais que as leis e os decretos não explicitassem, a ocupação de terras devolutas (sem considerar a população nativa) e a política de embranquecimento no Brasil sempre estiveram pautadas pela ideia de um modelo ideal europeu. Os imigrantes alemães, por exemplo, eram relacionados diretamente aos conceitos de civilização e antítese da brasilidade (SEYFERTH, 2002. p.118).

A imigração alemã no Brasil não foi um evento ocasional. Ela teve seu início no ano de 1824 e é mais frequentemente retratada em obras ficcionais de autores sulriograndenses, pois foi o sul do país que primeiro e em maior quantidade recebeu as levas dessa imigração. Porém, o grande projeto político de branqueamento da população no Brasil não se restringiu apenas ao sul. E os imigrantes alemães passam a ter um papel importante no país, refletindo-se também no campo literário.

O imigrante agricultor, juntamente com a sua família, era o alvo para a colonização do Brasil, principalmente no século XIX e ainda até meados do século XX. A construção de um país moderno e capitalista dependia do fim da escravidão, porém, os escravizados e seus descendentes não eram modelo ideal para esse fim.

No pensamento imigrantista do século XIX a escravidão não é percebida como um regime imoral ou ilegítimo, mas simplesmente adjetivada por seu caráter arcaizante, um modelo econômico retrógrado e impeditivo de imigração porque produz uma imagem negativa do país na Europa. (SEYFERTH, 2002. p.120)

O Brasil nunca esteve desabitado, e o confronto entre povos, culturas e línguas divergentes sempre foi grande. A Lei Áurea foi assinada em 1888, mas a assinatura de um papel não correspondeu à realidade. Quando da assinatura, a mensagem a ser transmitida é que os erros da História seriam ajustados. Contudo, nunca mudou a relação de exploração entre raças dentro do Brasil sob o pretexto de progresso e de evolução a qualquer custo. 


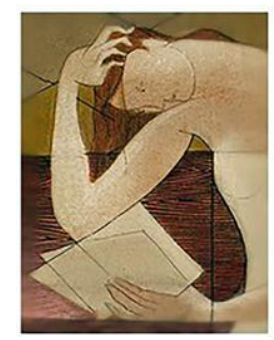

\section{Apresentação de Canã̃}

O tema do romance Canaã, escrito pelo diplomata maranhense José Pereira da Graça Aranha (1868-1931) é a imigração alemã. Canaã é ambientado no Espírito Santo, mais especificamente na cidade de Porto do Cachoeiro, a qual leva o nome de Santa Leopoldina nos dias de hoje.

Lançado no Brasil no ano de 1902, Canaã consiste em uma narrativa dividida em dez capítulos, sendo a principal personagem o imigrante alemão Milkau. Junto a Milkau, temos Lentz, outra personagem imigrante alemã, a qual diverge de Milkau no que se refere principalmente ao pensamento sobre o progresso do Brasil. O interesse em escrever um artigo tendo essa obra como foco foi a representação dos imigrantes alemães e de outras etnias em Canaã.

Ao longo de toda a narrativa há um incansável debate sobre a formação do nacional. Lentz acredita na superioridade da raça alemã, enquanto Milkau pensa que somente através da miscigenação dos povos é que um país poderá evoluir. Lentz fala o tempo todo em dominação e em superioridade dos brancos europeus e que somente eles poderiam fazer o Brasil crescer:

Mas isto é a lei da vida e o destino fatal deste País. Nós renovaremos a nação, nos espalharemos sobre ela, a cobriremos com os nossos corpos brancos e a engrandeceremos pela eternidade. [...] Falando-lhe com a maior franqueza, a civilização desta terra está na imigração de europeus: mas é preciso que cada um de nós traga a vontade de governar e dirigir. (ARANHA, 1998. p.31-32)

É curioso que Canaã tenha sido publicado em 1902 e apenas alguns anos depois eclodissem as duas grandes guerras mundiais. Nelas, sujeitos com ideias e sentimentos bastante semelhantes aos da personagem Lentz se multiplicariam e chegariam a produzir ações pautadas em superioridade e pureza da raça ariana.

Canaã é classificado por alguns estudiosos como um romance social (Lucia Miguel Pereira, 1973 in FOGAL; ARAÚJO, 2012). Isso se deve em primeiro lugar ao momento histórico em que o livro foi publicado: 1902. As consequências da abolição da escravatura são vividas a todo vapor concomitantemente ao grande número de imigrantes europeus já instalados no país e os que ainda estão chegando. Por outro lado, no início do século XX começam a ser debatidos assuntos que mais tarde serão tema 


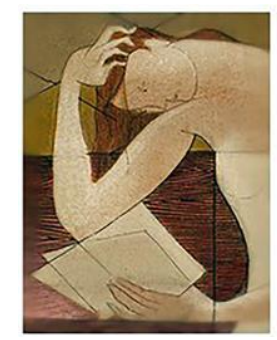

importante dos modernistas do movimento de 1922. O período em que mais são discutidas questões como a formação da identidade nacional e de como a imigração contribuiu para isso, por exemplo. Apenas a título de compreensão, mais tarde a ideia da cultura tropical surgirá através do choque de culturas, ou seja, o tema trazido por Graça Aranha em Canaã é algo discutido ainda nos dias de hoje.

A estilização dos aspectos históricos é uma marca de Canaã. O romance de Graça Aranha traz uma "polifonia de argumentos e perspectivas disfarçados sob a couraça racial" (FOGAL; ARAÚJO, 2012. p.131). O romance tem vários problemas, principalmente na ordem da estética, porém, é uma obra necessária à literatura brasileira.

Outra questão bastante recorrente ao longo da narrativa são os debates sobre a questão racial. A personagem Lentz traz na quase totalidade de suas falas a superioridade branca europeia. O imigrante alemão Milkau também aborda o tema, todavia sob um outro viés:

Um dos erros dos intérpretes da História está no preconceito aristocrático com que concebem a idéia de raça. Ninguém, porém, até hoje soube definir a raça e ainda menos como se distinguem umas das outras; fazem-se sobre isto jogos de palavras, mas que são como esses desenhos de nuvens que ali vemos no alto, aparições fantásticas do nada... E, depois, qual é a raça privilegiada para que só ela seja o teatro e o agente da civilização? Houve um tempo na História em que o semita brilhava em Babilônia e no Egito, o hindu nas margens sagradas do Ganges, e eles eram a civilização toda; o resto do mundo era a nebulosa de que se não cogitava. E, no entanto, é junto ao Sena e ao Tâmisa que a cultura se esgota hoje numa volúpia farta e alquebrada. O que eu vejo neste vasto panorama da História, para que me volto ansioso e interrogante, é a civilização deslocando-se sem interrupção, indo de grupo a grupo, através de todas as raças, numa fatal apresentação gradual de grandes trechos da terra, à sua luz e calor... Uns se vão iluminando, enquanto outros descem às trevas... (ARANHA, 1998. p.35)

Lentz tinha repulsa aos que não eram de sua raça, "olhava agora as duas raças, ali reunidas à mesa; admirava o que havia de sólido e repousado nos gigantes alemães, enquanto a facúndia interminável e mole do cearense e do mulato lhe trazia a sensação do enjoo do mar" (ARANHA, 1998. p.54). Esse é um aspecto que incomoda o leitor atento ao longo do livro, pois sempre que esse tipo de ideia surge não é tratada com repulsa, mas em tom de debate análogo, ou seja, como se a ideia fosse aceitável na mesma medida que as ideias de Milkau, por exemplo. 


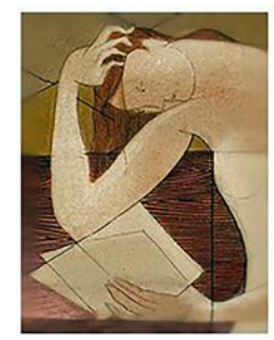

Na Parte V do livro, há o episódio de uma festa na comunidade de Jequitibá. Nesse momento, a personagem do agrimensor Felicíssimo, o qual é brasileiro, pede para que os músicos toquem um chorado, porém, eles não sabem tocar e arranjam um improviso. Ninguém, além de Felicíssimo e de Joca, se anima para a dança, e logo os músicos voltam a tocar o repertório das tradicionais bandinhas alemãs, para alegria de todos ali presentes.

Na Parte VIII do livro há uma discussão importante sobre o significado de Pátria. Para Lentz a Pátria é "a raça, uma civilização particular que nos fala no sangue, o nosso eu, a nossa própria projeção no mundo, a soma de nós mesmos multiplicados ao infinito" (ARANHA, 1998. p.149). Antes dessa definição, Lentz menciona com nostalgia a raça, o espírito belicoso e imperialista dos alemães. Mas para Milkau a palavra Pátria não faz sentido:

Não, meu querido Lentz, a Pátria é uma abstração transitória e que vai morrer... Sobre ela nada se fundou. Nem arte, nem religião, nem ciência. Nada, absolutamente nada tem uma forma elevada, sendo patriótico. O gênio humano é universal... A Pátria é o aspecto secundário das coisas, uma expressão da política, a desordem, a guerra. (ARANHA, 1998. p.149)

Há outros dois momentos bastante importantes na narrativa. O primeiro deles diz respeito à cobrança dos inventários por parte da Justiça brasileira aos alemães. Quem não havia registrado seus mortos em um prazo de trinta dias estava ilegal perante a lei. Os primeiros a precisar pagar uma quantia exorbitante são os membros da família de Franz Kraus. Os representantes da lei são brasileiros e, incompreendidos pelos alemães por não entenderem sua língua, caem fácil na sua mentira: "para que serve o colono senão para isso? Para sustentar e regalar a Justiça” (ARANHA, 1998. p.115).

É nessa família que vive Maria, a personagem por quem Milkau se apaixona e que é decisiva para o fechamento da narrativa. Maria foi adotada pela família Kraus porque seus pais morreram no navio que vinha ao Brasil. Ela vivia como empregada da família e mantinha uma relação escondida com o filho de Franz Kraus. A situação financeira da família ficou insuportável com a visita dos homens da justiça e, somado a isso tem início o martírio de Maria, que está grávida e é expulsa do povoado extremamente cristão sob o argumento de estar possuída pelo demônio, uma vez que 


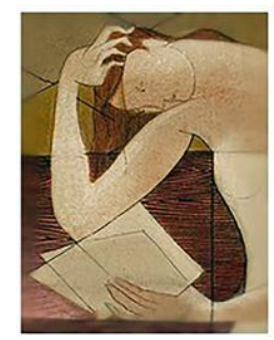

havia quebrado regras sagradas. Perambulando, Maria termina no armazém de Feliciano onde, em troca de três noites de pouso e comida, vende todas as suas vestes. Ali ela é encontrada e resgatada por Milkau, que a destina para trabalhar com uma outra família. O tratamento com uma mulher solteira e grávida não muda e o ápice do seu martírio se dá no momento em que o bebê nasce. Maria está trabalhando na lavoura de café quando sente as contrações. Fraca e com muita dor ela decide ter o bebê sozinha embaixo de uma árvore. Porém, quando finalmente consegue parir a criança, ela desmaia e uma manada de porcos selvagens toma a criança de Maria e a come viva. Uma moça visualiza a cena e sai espalhando a mentira de que a própria Maria teria dado o filho aos porcos. Maria é presa. Até o seu julgamento, Milkau a visita inúmeras vezes até que resolve fugir e buscar junto com ela a prometida Canaã.

Esses dois episódios são importantes pelas caricaturas que oferecem ao leitor. Por um lado, temos a Justiça brasileira pintada como corrupta e abusiva, que não é séria e nem organizada e que se aproveita dos pobres imigrantes alemães em vários sentidos. Por outro, temos uma personagem vítima do destino, nascida para sofrer, injustiçada pelo amor proibido e que sofre a tragédia de perder um filho da forma como o foi. Diante de todas as lutas e sofrimentos, ela é resgatada no final para buscar a terra de Canaã, merecida por ela e por Milkau.

\section{A personagem Milkau}

Canã̃ em termos bíblicos é a terra prometida. Milkau é um imigrante alemão que veio ao Brasil com o intuito de trabalhar no campo. Ainda na Alemanha ele já tinha várias questões filosóficas e, depois que a mãe morreu não viu mais muito sentido na vida, a ponto de cogitar o suicídio. Todavia, vendo a Beleza da Arte começou a perceber também a grandiosidade da Natureza e, por isso, veio ao Brasil. A compreensão total de o livro ter levado esse nome é completa bem no final do romance, quando Milkau e Maria fogem em busca da terra prometida e não a encontram.

O nome Canaã pode ser compreendido pelo desejo de Milkau em unir as raças e formar uma só, uma “cidade universal". Milkau é uma personagem que tem sonhos 


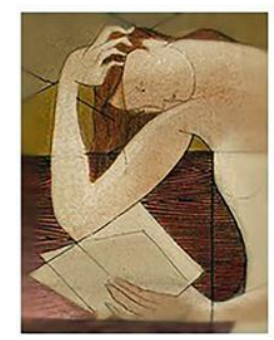

utópicos ao mesmo tempo em que divide o seu tempo e seus diálogos com Lentz, personagem essa que diverge completamente das utopias de Milkau.

\section{A personagem Lentz}

Lentz só aparece na narrativa junto a Milkau. Lentz queria ser comerciante, mas acabou tendo como função a caça e a pesca, pois morando com Milkau se negava a trabalhar na lavoura. Ele acreditava na superioridade da raça alemã e que poderia formar um "império branco" no Brasil. Lentz deixou a Alemanha porque deflorou a filha de um militar e teve de fugir.

Tudo no Brasil que seja característico do país incomoda Lentz. Até mesmo a floresta brasileira era para Lentz sinônimo de selvageria, de desordem e de retrocesso.

E Lentz via por toda a parte o homem branco apossando-se resolutamente da terra e expulsando definitivamente o homem moreno que ali se gerara. E Lentz sorria com orgulho na perspectiva da vitória e do domínio de sua raça. Um desdém pelo mulato, em que ele exprimia o seu desprezo pela languidez, pela fatuidade e fragilidade deste, turvou-lhe a visão radiosa que a natureza do país lhe imprimira no espírito. Tudo nele era agora um sonho de grandeza e triunfo... Aquelas terras seriam o lar dos batalhadores eternos, aquelas florestas seriam consagradas aos cultos temerosos das virgens ferozes e louras... Era tudo um recapitular da antiga Germânia. Ele percebia no seu cérebro exaltado que os alemães chegariam, não em pequenas invasões humildes de escravos e traficantes, não para lavrar a terra para recreio do mulato, não para mendigar a propriedade defendida pelos soldados negros. Eles viriam agora em grandes massas; galeras imensas e numerosas os desembarcariam em todo o país. Eles viriam numa ânsia de posse e de domínio, com sua áspera virgindade de bárbaros, em cortes infinitas, matando os homens lascivos e loucos que ali se formaram e macularam com suas torpezas a terra formosa; eles o eliminariam com o ferro e com o fogo; eles se espalhariam pelo continente, fundariam um novo império, se revigorariam eternamente na força da natureza que dominariam como uma vassala, e senhores, e ricos, e poderosos, e eternos repousariam para sempre na alegria da luz. (ARANHA, 1998. p.65)

Tanto Lentz quanto Milkau almejam uma vida no Brasil que não conseguem ter. Bakhtin (2019, p.107) afirma que "um dos temas internos basilares do romance é precisamente o tema da inadequação da personagem ao seu destino e à sua situação". O romance Canã̃ se desenvolve pelas ideias de vida nova em um país novo para os dois imigrantes alemães. Lentz pela dominação da raça e Milkau pela miscigenação e conquista da terra prometida. 


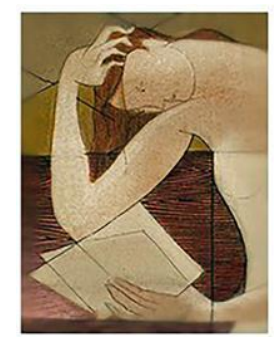

\section{A representação do negro em Canã̃}

Canaã é um romance cujo tema narrativo é a imigração alemã. A imigração é retratada num lugar do Brasil onde o período escravocrata foi muito intenso. Todavia, são raríssimos os momentos em que há contato de alemães com negros na narrativa.

Nos momentos em que aparece alguma personagem negra, ela vem também sem ser nomeada. É curioso que esse tipo de personagem quase não apareça, ao mesmo tempo em que é justificável por termos uma narrativa pautada na comunidade imigrante e nas personagens alemãs. Considerando a história da imigração alemã no Brasil, "a ausência de negros e mestiços na maioria das áreas coloniais foi atribuída ao preconceito racial dos imigrantes e de diretores de empresas colonizadoras" (SEYFERTH, 2002. p.120). Sempre que referidas na narrativa, as personagens locais são adjetivadas como primitivas, até mesmo por Milkau.

Logo no começo da narrativa, quando Milkau e Lentz estão se deslocando para o seu destino (Porto do Cachoeiro), encontram um rancho de moradores no povoado de Queimado. Lá estão um velho cafuzo, uma mulata moça cafuza e um negrinho, como se refere o narrador. Milkau é chamado pelo velho cafuzo de "meu sinhô" e, ao apear do cavalo e fazer algumas perguntas ao velho sobre a história daquele lugar, o cafuzo the fala em tom de nostalgia dos tempos em que era escravo na casa do capitão Matos. Fala das festas com a casa cheia de escravos, dos trabalhos e castigos.

As personagens negras aparecem sempre com sentimentos de nostalgia em um tempo em que, apesar de todas as violências como a existência dos feitores, por exemplo, havia um teto, comida e festa com tambor no domingo.

“- Ah, tudo isso, meu sinhô moço, se acabou... Cadê fazenda? Defunto meu sinhô morreu, filho dele foi vivendo até que Governo tirou os escravos. Tudo debandou. Patrão se mudou com a família para Vitória, onde tem seu emprego; meus parceiros furaram esse mato grande e cada um levantou casa aqui e acolá, onde bem quiseram. Eu com minha gente vim para cá, para essas terras do seu coronel. Tempo hoje anda triste. Governo acabou com as fazendas, e nos pôs todos no olho do mundo, a caçar de comer, a comprar de vestir, a trabalhar como boi para viver. Ah! tempo bom de fazenda! A gente trabalhava junto, quem apanhava café apanhava, quem debulhava milho debulhava, tudo de parceria, bandão de gente, mulatas cafuzas... Que importava feitor?... Nunca ninguém morreu de pancada. Comida sempre havia, e quando era sábado, véspera de domingo, ah! meu sinhô, tambor velho roncava até de madrugada... (ARANHA, 1998. p.17) 


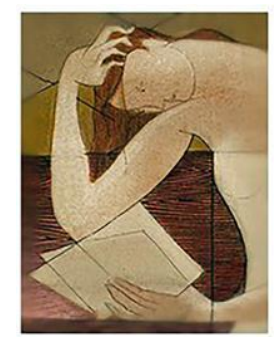

Porém, nos raros momentos em que alguma personagem negra tem voz na narrativa, não o faz apenas em tom de nostalgia ou de subserviência. No capítulo VI aparece uma personagem não nomeada, apenas qualificada como "um mulato montado numa besta" que tenta se comunicar com Franz Kraus para lhe entregar um mandato da Justiça. Este não compreende o que está escrito pois não está familiarizado com a língua, ao passo que o mulato diz "também vocês vivem aqui na terra a vida inteira e estão sempre na mesma, bradou o mulato. Venho por aqui furando este mundo, e de casa em casa sempre a mesma coisa: ninguém sabe a nossa língua... Que raça!” (ARANHA, 1998. p.109).

\section{Conclusão}

Apenas um bom tempo depois é que textos com a temática negra em primeiro plano e escritos por autores não pertencentes ao cânone - e que não se encaixam no cânone porque a tradição desde sempre comprometeu essas vozes - começam a ser descobertos e também a serem mais produzidos e lidos. Tais sujeitos não fazem um texto experimental. Não há grande subjetividade ou rebuscamento porque o que precisam falar é da ordem da linguagem direta, ou seja, sem rodeios. É possível afirmar que, a partir disso, está se construindo uma nova tradição literária, mas não modernista, porque também nesse movimento os negros não foram incluídos.

Quando refletimos sobre a questão da mulher negra na literatura - escritora ou protagonista do enredo -, o problema se torna ainda mais sensível, pois há o perigo de cair na estereotipia. Na produção literária de homens e mulheres afrobrasileiros a questão da revisão da história é muito presente. Talvez por isso os negros não tenham tanta representatividade na tradição literária brasileira - a ponto de termos romances como Canaã.

A margem tem vários lados: o gênero, a cor, a classe social... Na literatura não é diferente. Os sujeitos agora livres estavam desamparados, como pudemos ver em Canaã. Os reais danos da escravização nunca foram reparados; o fim desse período nefasto da história do Brasil não pôs fim à miséria. A instituição do escravismo acabou, mas o latifúndio vive até hoje; quem detém os meios de produção são majoritariamente 

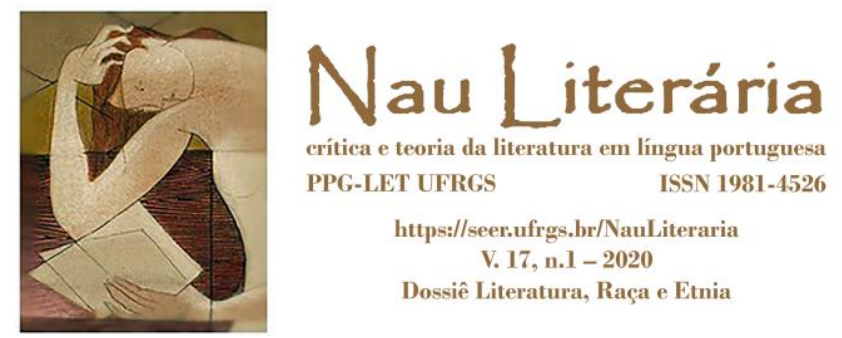

pessoas brancas e muitas delas são do grupo de imigrantes que vieram para o Brasil quando ele ainda era escravocrata. Assim é possível entender um pouco das representações de raça também na literatura.

\section{Referências}

ARANHA, Graça. Canaã. São Paulo: Ática, 1998.

BAKHTIN, Mikhail. Teoria do romance III: O romance como gênero literário. Trad. Paulo Bezerra. São Paulo: Editora 34, 2019.

FOGAL, Alex Alves. ARAÚJO, Bárbara Del Rio. A estilização da imigração em Canaã, de Graça Aranha. Literatura em debate, v. 6, n. 10, p. 126-138, agosto de 2012. http://revistas.fw.uri.br/index.php/literaturaemdebate/article/view/628. Acesso em: 15 mar 2020.

HUNT, Lynn. A invenção dos direitos humanos; uma história. Trad. Rosaura Eichenberg. São Paulo: Companhia das Letras, 2009.

SEYFERTH, Giralda. Colonização, imigração e a questão racial no Brasil. Revista USP, São Paulo, n. 53, p. 117-149, mar./maio, 2002. https://doi.org/10.11606/issn.23169036.v0i53p117-149. Acesso em: 15 mar 2020. 